\title{
Recordando a Patricio Núñez Henríquez
}

\author{
Rodolfo Contreras Neira ${ }^{1}$
}

Como no recordar a Patricio Núñez, su carismática e imponente presencia y de una profunda humildad y sencillez en el trato con todos aquellos que se acercaban a él atraídos por sus conocimientos sobre la naturaleza humana, la prehistoria, la historia, el arte y principalmente por su calidez, su espíritu integrador, colaborativo y amable con todos aquellos que lo conocieron.

Conocí a Patricio a mi llegada a Taltal en el 2002 cuando iniciaba el sueño de formar un museo que reflejara la importancia de la historia de esta localidad y de su patrimonio cultural, en una ciudad deprimida por la constante crisis económica de la minería, que constituía una de sus principales actividades productivas. En esos años, la Universidad de Antofagasta efectuaba en el mes de julio en el marco del aniversario de la ciudad la "Escuela de Temporada", actividad de extensión que se venía realizando desde 1994 impartiendo cursos y talleres en diversas áreas temáticas, esencialmente orientados a la comunidad.

El Instituto de Investigaciones Antropológicas, cuyo director era Patricio, participaba con la organización de charlas sobre prehistoria e historia del Norte Grande junto a exposiciones sobre arqueología y el arte andino. Asistían a estas actividades personas de distintas profesiones, estudiantes, dueñas de casa, pescadores y mineros, todos atraídos por la inquietud de conocer de la historia pasada y presente de la región, pero principalmente, por la simplicidad y atracción que ejercía Patricio al comunicar conocimiento de manera simple y relacionarlo con las problemáticas sociales y culturales contemporáneas de la ciudad puerto. La "orientación social del conocimiento" era para Patricio una prioridad en su ejercicio académico. Sabía, que era necesario interesar y motivar a la comunidad, principalmente a los jóvenes y niños como actores activos en los cambios posibles de realizar en la realidad circundante, en una ciudad alejada de los principales centros urbanos y carentes de oportunidades de desarrollo.

Al mismo tiempo, como antropólogo social, visualizaba el proyecto de formación de un museo en la ciudad de Taltal como una acción participativa, donde los actores sociales tuvieran un rol activo en los procesos de valoración del patrimonio local y formación de colecciones, de manera de dar sustento en el tiempo a un proyecto museológico de carácter municipal. En este punto coincidimos con Patricio e iniciamos un fructífero trabajo en conjunto, reuniendo a las autoridades locales y la comunidad, organizada en torno a la materialización de nuestras acciones profesionales, esencialmente humanistas y sociales.

Como resultado de las charlas y exposiciones realizadas por Patricio durante varios años en Taltal, nace en torno a su figura un grupo de jóvenes que motivados por sus enseñanzas, ven en el patrimonio cultural una vía de cambio social y cultural al dar sentido a su relación con los objetos arqueológicos, para transformarlos, en bienes culturales identitarios al servicio y deleite de la comunidad y de los visitantes turísticos. Así, nace la "Agrupación Comunitaria Amigos del Museo Augusto Capdeville", conformada principalmente por aquellos jóvenes y niños que asistieron y conocieron a Pato en esos años y fueron fieles seguidores de su persona hasta sus últimos días.

Fue así, que nuestra primera salida a terreno junto a la Agrupación Comunitaria fue en el marco de la caracterización de sitios arqueológicos del sector "Pelao Sae" al sur de Taltal. Obra, que consideraba el mejoramiento de caminos de la comuna con la finalidad de facilitar el acceso de los pescadores recolectores a nuevas áreas productivas. Recuerdo la participación en esa oportunidad de Hugo Garate, Marcelo Morales, Mauricio Ríos, Rebeca Salinas, Omar Rodríguez junto a sus hijos Omar, Marcelo y Seba quienes motivados por Patricio, participaban en cada una de las tareas arqueológicas, quien desinteresadamente, entregaba sus conocimientos sobre la naturaleza humana, la historia, la arqueología y la importancia del cuidado y resguardo de nuestro patrimonio como parte fundamental de nuestra identidad a este variado grupo de amigos, y por un instante, alumnos atentos y respetuosos.

En esa ocasión, pude conocer en terreno la preocupación de Pato por la conservación de los

${ }^{1}$ Museo Augusto Capdeville Rojas, Avenida Arturo Prat 5, Taltal, Chile. museo.taltal@gmail.com 
sitios arqueológicos y su puesta en valor para el conocimiento por parte de la comunidad. Para Pato, toda intervención arqueológica debiera considerar aspectos de conservación del sitio intervenido por sus características patrimoniales, por su valor histórico, arquitectónico y estético. Se interviene el sitio TSTA002, que correspondía a un campamento de pescadores, cazadores y recolectores marinos que se caracterizaba por la presencia de estructuras circulares superficiales constituidas a modo de "pirca seca" de tradición tardía, deterioradas por causas naturales y por la intervención humana. Pato, propone aplicar una metodología de preservación de cinco estructuras habitacionales utilizando una estrategia de rescate parcial de un sitio arqueológico, dejando un testimonio vivo de la arquitectura habitacional de los grupos humanos que habitaron el lugar en periodos tardíos, con el propósito, de dignificar un modelo de habitar el espacio y principalmente como una intervención concreta para el conocimiento de un periodo de la prehistoria y el desarrollo del turismo cultural en Taltal. En ese sentido, Pato fue consecuente con sus ideales de los años setenta, al pensar "La Arqueología como Ciencia Social", considerando la posibilidad de ver en la disciplina una plataforma de cambio, donde el patrimonio arqueológico, luego de ser estudiado por los especialistas, pueda constituirse como una herramienta efectiva para generar cambios estructurales, principalmente en este caso con el desarrollo de un turismo de intereses especiales (Goñi y Núñez 1971; Núñez 1976; Núñez et al. 2001).

Posteriormente, una intervención de las mismas características realizamos en los Bronces-1, sitio arqueológico del Arcaico Tardío con estructuras habitacionales tipo Huelén-42, donde junto a Pato y la Agrupación Comunitaria invitamos a participar a profesionales de diversas instituciones académicas de la región. Agustín Llagostera y Héctor Garcés de la Universidad Católica del Norte, Julio Cruz del Museo Regional de Antofagasta y Gabriel Becerra arquitecto y pintor, quienes se integran a la Agrupación Comunitaria formando un variado grupo de personas unidos por el amor y respeto al patrimonio cultural. Luego de la intervención del sitio, propusimos con Patricio un proyecto de continuidad, con la finalidad de poner en valor social y cultural el sitio arqueológico como resultado de una acción participativa, entregando al Municipio local el Museo de Sitio los Bronces-1 para su administración, como una experiencia conjunta entre la comunidad y la academia para el desarrollo del turismo en torno al patrimonio.

Recuerdo otras actividades que realizamos juntos con la participación activa de la Agrupación de Amigos del Museo de Taltal como; Catastro de las pinturas rupestres del área de Taltal, la puesta en valor del cerro Mirador en Paposo, visita a los sitios arqueológicos de la costa de Chañaral, excavaciones arqueológicas en Punta Negra en la costa de Paposo entre otros. En Punta Negra, Patricio se emociona al descubrir la "Huaca de Punta Negra-1c", centro ceremonial costero del Arcaico Tardío vinculado al mundo mágico y religioso de las comunidades costeras. En su análisis interpretativo del sitio, relaciona la arqueología con la filosofía, el arte, la estética y la religión, plasmando sus resultados en un maravilloso libro titulado "Vivir después de soñar".

Esta capacidad soñadora e integradora de voluntades que tenía Pato, de unir a las personas por una causa común, es una característica difícil de encontrar en las nuevas generaciones que, encerrados en sus propias cavilaciones exitistas, no logran integrar sus conocimientos "al todo social". Cuán difícil es hoy en día, incorporar a otros de manera desinteresada a nuestro quehacer profesional y entregar nuestros conocimientos de manera sencilla y cautivadora a la comunidad como él tan bien lo hacía. Patricio estaba sobre estas pequeñeces, para él, la arqueología así como la antropología son ciencias sociales y humanistas, no se puede perder de vista lo esencial de nuestras disciplinas, al ser humano y a las sociedades que constituyen nuestro objeto de estudio. Para Patricio, los artefactos son solo un camino para conocer el pensamiento y el mundo espiritual de las comunidades humanas.

Gracias Pato por haber tenido la posibilidad de conocerte, gracias por tus enseñanzas de lo humano y del verdadero sentido de la vida. Gracias Pato, te llevaré siempre en mis pensamientos y en el alma. Un gran abrazo querido amigo. 


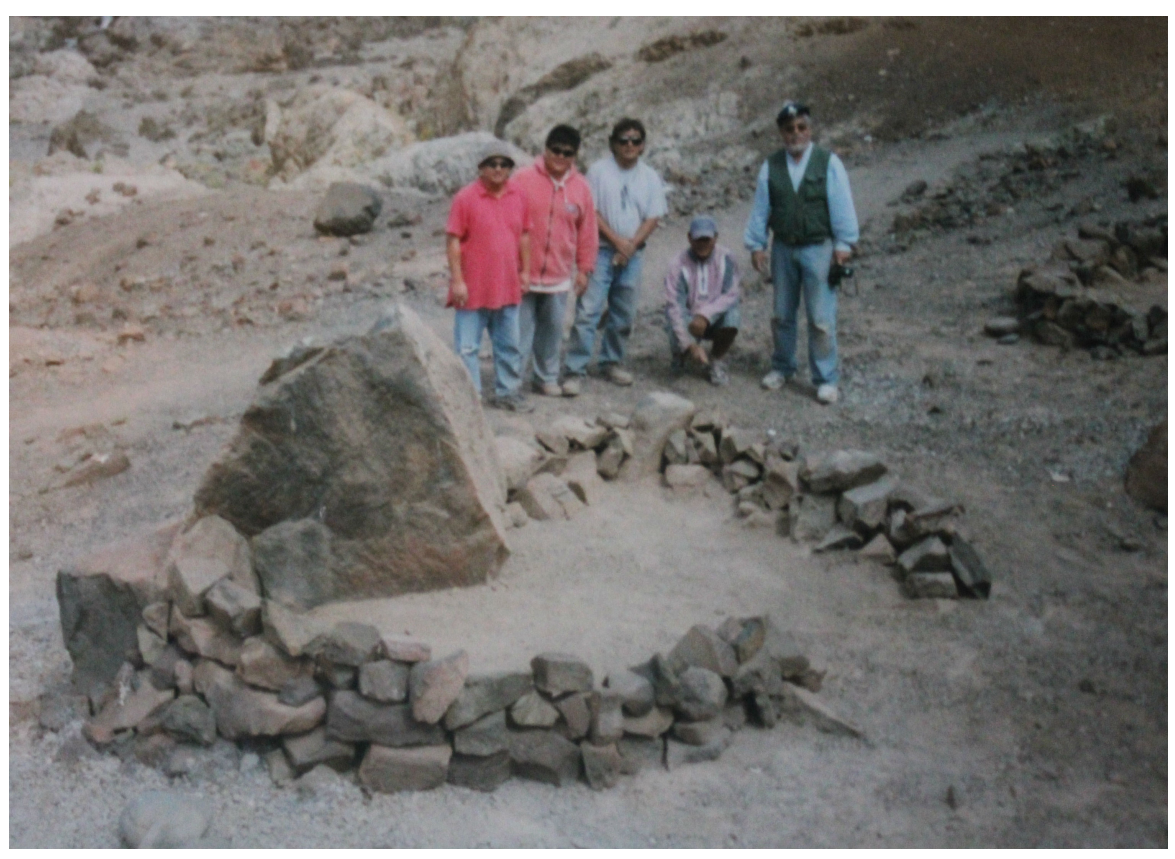

Trabajo de campo y caracterización de sitios arqueológicos del sector del "Pelao Sae" al sur de la ciudad de Taltal. Fotografía del sitio arqueológico TSTA002 después de la conservación de las estructuras. Vemos a Patricio Núñez junto a los integrantes de la Agrupación Comunitaria, Marcelo Morales (Chelo) en cuclillas, Omar Rodríguez, Mauricio Ríos y Hugo Garate frente a una de las estructuras habitacionales, año 2003 (archivo fotográfico Museo Augusto Capdeville, Taltal).

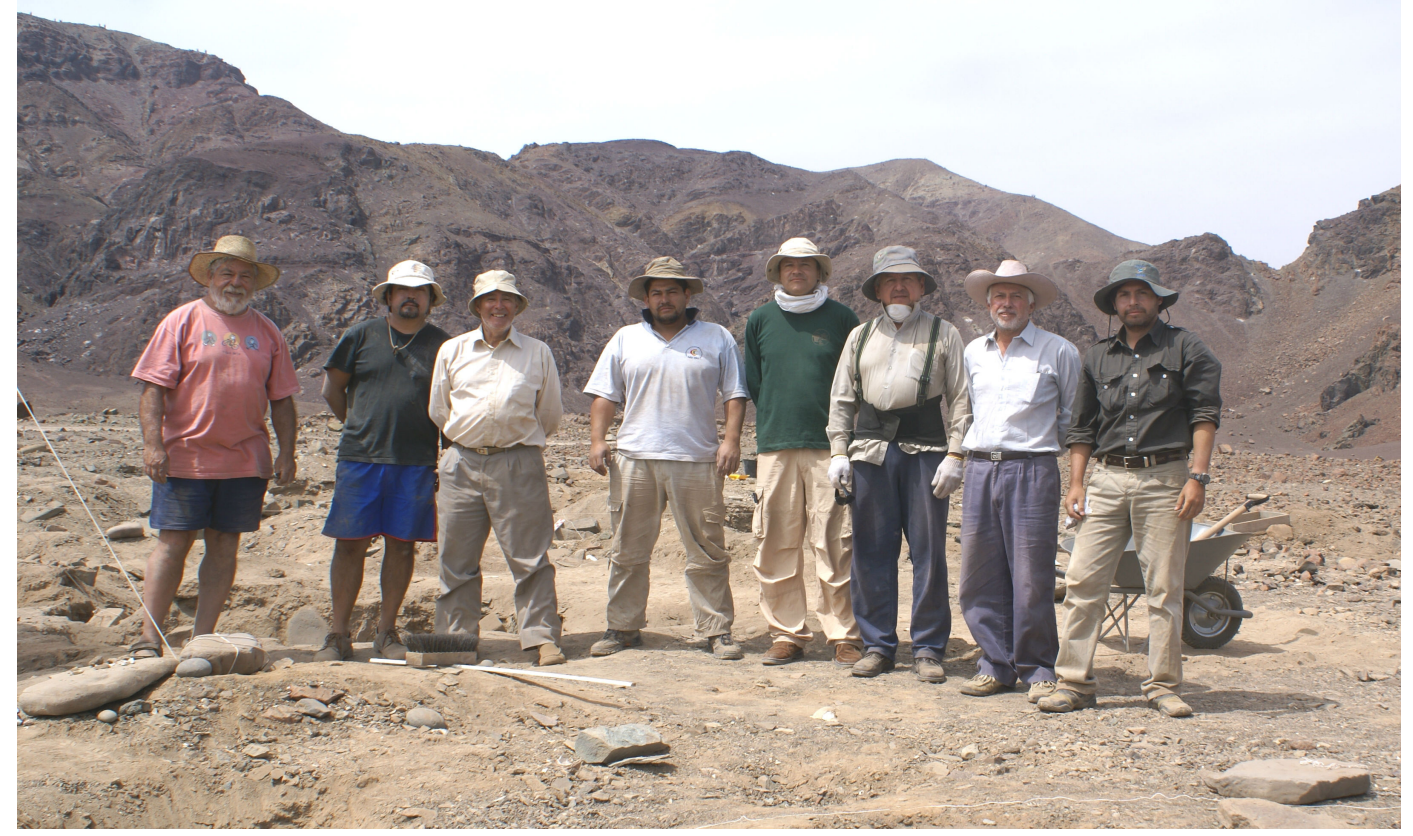

Temporada de campo y excavaciones en el sitio arqueológico Los Bronces-1 al sur de Taltal en el 2009. De izquierda a derecha, Patricio Núñez de la Universidad de Antofagasta; Omar Rodríguez dibujante, Héctor Garcés de la Universidad Católica del Norte, Hugo Garate historiador, Rodolfo Contreras del Museo Augusto Capdeville, Julio Cruz del Museo Regional de Antofagasta, Agustín Llagostera de la Universidad Católica del Norte y Gabriel Becerra arquitecto y pintor, año 2007 (archivo fotográfico Museo Augusto Capdeville, Taltal). 


\section{Referencias Citadas}

Goñi, A. y P. Núñez 1971. Cueva 85, Distrito Tahai, Isla de Pascua. En Actas del VI Congreso Nacional de Arqueología Chilena, pp. 371396. Boletín de Prehistoria de Chile, Número Especial, Santiago.

Muñoz, E., P. Núñez y M. Bahamondes 2001. Conservación y Restauración del Sitio Arqueológico $N^{\circ} 19$ de San Pedro de Atacama.
Ministerio de Educación, Consejo de Monumentos Nacionales, Santiago.

Núñez, P. 1976. En torno a la arqueología y la restauración monumental. Serie Documentos de Trabajo 7:9-14. 